\title{
Neurobiological actions by three distinct subtypes of brain-derived neurotrophic factor: Multi-ligand model of growth factor signaling
}

Toshiyuki Mizui $^{1,3, *}$, Yasuyuki Ishikawa ${ }^{2,3}$, Haruko Kumanogoh ${ }^{1,3}$, Masami Kojima ${ }^{1,3,}$

1. Biomedical Research Institute, Advanced Industrial Science and Technology (AIST), Osaka, 563-8577, Japan.

2. Department of Systems Life Engineering, Maebashi Institute of Technology, Gunma 371-0816, Japan.

3. Core Research for Evolutional Science and Technology (CREST), Japan Science and Technology Agency (JST), Kawaguchi, 332-0012, Japan

* Correspondence should be addressed to M.K. (m-kojima@aist.go.jp) and T.M.

(t-mizui@aist.go.jp)

T.M. H.K., Y.I., M.K. wrote the paper; T.M. and M.K. conceived and supervised this paper.

The authors have no competing financial interests to declare.

Keywords: BDNF, pro-peptide, polymorphism, long-term depression, hippocampus 


\begin{abstract}
Brain-derived neurotrophic factor (BDNF) is one of the most active members of the neurotrophin family. BDNF not only regulates neuronal survival and differentiation, but also functions in activity-dependent plasticity processes such as long-term potentiation (LTP), long-term depression (LTD), learning, and memory. Like other growth factors, BDNF is produced by molecular and cellular mechanisms including transcription and translation, and functions as a bioactive molecule in the nervous system. Among these mechanisms, a particular post-translational mechanism, namely the conversion of precursor BDNF into mature BDNF by proteolytic cleavage, was not fully understood. In this review, we discuss the manner through which this post-translational mechanism alters the biological actions of BDNF protein. In addition to the initially elucidated findings on BDNF, the biological roles of precursor BDNF and the BDNF pro-peptide, especially synaptic plasticity, will be extensively discussed. Recent findings on the BDNF pro-peptide will provide new insights for understanding the mechanisms of action of the pro-peptides of growth factors.
\end{abstract}




\section{The neurotrophin family}

Neurotrophins (NTs), which historically emerged as trophic proteins for promoting neuronal survival and differentiation, were recently studied as a class of modulators of synaptic transmission and plasticity $(1,2)$.

In the 1950s, Levi-Montalcini and Hamburger discovered that a mouse sarcoma tumor implanted near the spinal cord of the developing chicken released a protein that increased neurite outgrowth from sympathetic neurons (3). Later, this factor was named nerve growth factor (NGF) (4) (5) (6). Their discovery played a pioneering role in the research of developmental neurobiology, which provided a new notion that target-derived secreted proteins control neuronal numbers and neurite growth. Over 20 years after the discovery of NGF, Barde et al. (1982) isolated a neuronal survival-eliciting factor from the pig brain, named brain-derived neurotrophic factor (BDNF) (7). In 1989, the full primary structure of BDNF and its expression in brain was identified (8), and BDNF was found to be highly homologous to NGF at the level of the amino acid sequence. Using the new technology of polymerase chain reaction (PCR), neurotrophin-3 (NT-3) (9) and neurotrophin-4/5 (NT-4/5) (10), whose amino acid sequence is highly homologous to NGF and BDNF as well, were molecularly cloned. Lastly, the four NTs and their genes showed marked homology to each other in terms of sequence and structure (11).

The discoveries of NT family members provided important insights into the formation of neuronal communication during the development of the nervous system and into synaptic plasticity, memory, and learning in the adult brain. Moreover, specific neuronal populations require the presence of one or more NTs, and their roles are exerted spatially-and temporally. Furthermore, there are long- and short-term actions of NTs. The long-term trophic actions depend on gene regulation, whereas short-term effects, including chemotrophic effects on developing neurons and synaptic transmissions, are controlled by the activation of cytoplasmic effectors by NTs.

\section{NT receptors and their signaling}

Like most growth factors, NTs are initially synthesized as precursors (pro-neurotrophins) composed of approximately 270 amino acids. The protein products of NTs are structurally composed of a signal sequence, a pro-domain, and the mature domain. To produce the mature and bioactive form, the N-terminal fragment of 
approximately 120 amino acids, or the "pro-domain”, is proteolytically processed by intracellular and/or extracellular proteolytic enzymes (e.g., furin, pro-hormone convertase, and plasmin) (12-15). Several reports explored the intracellular mechanisms of NT processing. In neurons, the N-terminal pro-domain is proteolytically processed, either in the trans-Golgi by furin or in secretory granules by intracellular proteinases, to generate the mature form of neurotrophins, while in non-neuronal cells, neurotrophins are constitutively secreted (12). However, secretion of BDNF is controlled by both constitutive and activity-regulated secretion pathways in neurons (16), and the secretion of BDNF is controlled in a neuronal activity- and $\mathrm{Ca}^{+}{ }^{+}$-dependent manner (reviewed by (17)). The activity-dependent secretion of BDNF may be a critical mechanistic step in controlling synaptic transmission and long-term synaptic plasticity.

\section{NT receptors and their signaling}

There are two distinct classes of NT receptors. The first receptor, the p75 neurotrophin receptor $\left(p 75^{\mathrm{NTR}}\right.$ ), is a member of the tumor necrosis factor (TNF) receptor family (18). Initially, $\mathrm{p} 75^{\mathrm{NTR}}$ was discovered as a low-affinity NGF receptor, but was subsequently found to bind to BDNF, NT-3, and NT-4/5 with a similar affinity (18). The extracellular domain of $\mathrm{p} 75^{\mathrm{NTR}}$ has cysteine-rich motifs. The cytoplasmic domain includes a 'death' domain, which is also found in the cytoplasmic domain of other members of the TNF receptor family $(19,20)$. Although $\mathrm{p} 75^{\mathrm{NTR}}$ does not contain a catalytic kinase motif, it interacts with many proteins that transmit signals important for the regulation of neuronal survival and differentiation (18) (21). The $\mathrm{p} 75^{\mathrm{NTR}}$ receptor activates three major signaling pathways. First, NF-kappa B activation leads to transcription of multiple genes, including several that promote neuronal survival. Second, activation of the Jun kinase pathway similarly controls the activation of several genes, some of which promote neuronal apoptosis. Third, ligand engagement of $\mathrm{p} 75^{\mathrm{NTR}}$, through the regulation of Rho activity, controls the motility of growth cone (22).

The second class of NT receptors is the tropomyosin-related kinase (Trk) family of receptor tyrosine kinases (TrkA, TrkB, and TrkC) (22). Each NT binds to a specific Trk receptor: NGF binds to TrkA, BDNF and NT-4/5 to TrkB, and NT-3 to TrkC. The Trk receptors have a trans-membrane region that spans the plasma membrane and a cytoplasmic domain that has tyrosine kinase activity. Binding of an NT to a specific Trk receptor activates its tyrosine kinase, leading to the activation of the 
phosphatidylinositol 3-kinase (PI3K), mitogen-activated protein kinase (MAPK), and phospholipase C- $\gamma$ (PLC- $\gamma$ ) pathways. Activation of Ras leads to activation of the MAP kinase-signaling cascade, which promotes neuronal differentiation, including neurite outgrowth. Activation of $\mathrm{PI}_{3}$ kinase through Ras or Gab1 promotes survival and growth of neurons and other cells. Activation of PLC- $\gamma$ results in activation of protein kinase C-controlled pathways that promote synaptic plasticity (22). Many additional adaptors for $\mathrm{p} 75^{\mathrm{NTR}}$ and Trk receptors have been reported. Information about the two types of NT receptors and their signaling mechanisms has been extensively reviewed by others (e.g., see (23) (18) (22) (24) (25)) and will not be further discussed in this review.

\section{Synaptic plasticity, long-term potentiation (LTP), and BDNF}

Since BDNF mRNA is expressed in the brain, including the hippocampus and cortex (8), the role of BDNF in synapse function has been intensively investigated (2). Synaptic plasticity is thought to be critical for the processing and encoding of information by neuronal networks, which is central to learning and memory (26). LTP and long-term depression (LTD) are forms of activity-dependent synaptic plasticity that increase or decrease the strength of synaptic transmission, respectively (reviewed by (27)). LTP and LTD can be categorized into at least two distinct phases: early-LTP/LTD (E-LTP/LTD) and late-LTP/LTD (L-LTP/LTD). E-LTP and L-LTP are corresponded to short-term memory and long-term memory, respectively. E-LTP occurs during the first hour or two of LTP and can be induced by a high-frequency tetanus stimulation (100 pulses at 100 $\mathrm{Hz}$ ), increasing the strength of synaptic transmission and activating signaling molecules such as protein kinases, while L-LTP persists for longer and involves de novo synthesis of plasticity-related proteins (PRPs) (28) (29). E-LTD is usually induced by low-frequency stimulation (LFS; $1 \mathrm{~Hz}, 900$ pulses, 15 min).

Although NTs were originally identified as a family of protein factors that regulate neuronal survival and differentiation, a number of studies show that neurotrophins play roles in the development and function of synapses (reviewed by (2)). The function of BDNF in synaptic transmission and plasticity in the hippocampus has been extensively investigated. Both expression and secretion of BDNF are controlled by neuronal activity and excitatory transmission (30) (31) (32) (33) (34) (35). Acute application of exogenous BDNF increases neuronal activity and synaptic transmission in primary cultured neurons (36) (37), suggesting the modulation of synaptic function by BDNF. 
Consistent results elucidate the role of BDNF in the LTP. Application of exogenous BDNF facilitates LTP induction in neonatal hippocampal slices (38). However, treatment with TrkB-IgG, a fusion protein that scavenges endogenous BDNF, decreases the magnitude of LTP in adult hippocampal slices with high levels of endogenous BDNF (38) (39). The role of BDNF in hippocampal synaptic plasticity has also been explored using BDNF knockout mice. Although the homozygous (-/-) mice exhibit growth retardation and other impairments, there is no obvious neuronal loss in the hippocampus (40) (41). While heterozygous (+/-) mice do not exhibit striking behavioral abnormalities, severe impairment in hippocampal LTP is observed (42) (43). The heterozygous $(+/-)$ mice show the same degree of impairment as the homozygous $(-/-)$ mice, suggesting that a critical level of BDNF is required for the expression of hippocampal LTP. Importantly, the impairment in the hippocampal LTP is restored after incubation with recombinant BDNF (42) or by virus-mediated BDNF gene transfer (44), showing that a dysfunction of BDNF, rather than cumulative developmental abnormalities, causes the impairment of hippocampal LTP in the BDNF knockout mice.

Moreover, the synaptic functions of the mature forms of NTs contribute to the activation of Trk receptors rather than $\mathrm{p} 75^{\mathrm{NTR}}$. For instance, regulation of neurotransmitter release at neuromuscular synapses by NT-3 requires TrkC and subsequent simultaneous activation of PI3K and the phospholipase C (PLC)- $\gamma /$ inositol triphosphate (IP3) signaling pathways (45). In the hippocampus, inhibition of p75 does not block BDNF regulation of presynaptic function or LTP (46). Mutation of TrkB receptors at the PLC- $\gamma$ docking site, but not at the Shc docking site, resulted in a deficit in hippocampal LTP (47).

\section{The role of BDNF in excitatory-inhibitory synaptic activity}

The relationship between BDNF action and the balance of excitatory-inhibitory synaptic activity is an important issue in the field of synaptic plasticity (2). Glutamate receptors, including N-methyl-D-aspartate (NMDA) and non-NMDA receptors, exert distinct roles in synaptic plasticity. BDNF signaling through the TrkB receptor leads to the phosphorylation of the NR1 and NR2B subunits of the NMDA receptor (48) (49) and up-regulates the GluR1 subunit of the alpha-amino-3-hydroxy-5-methyl-4-isoxazolepropionic acid receptor (AMPAR), as well as the GluR2/3 subunits (50). It was further shown that BDNF decreases the excitability 
of gamma aminobutyric acid (GABA)ergic inter-neurons through the activation of TrkB, while proBDNF does not affect GABAergic activity (51). However, at least in some conditions, GABAergic function exerts a crucial role in the regulation of the induction of LTP and LTD (52).

\section{Precursor and polymorphism of neurotrophins}

Although the biological roles of mature form of NTs are well characterized, the roles and functions of precursor forms of NTs and their pro-domains are ill-defined. In $21^{\text {st }}$ century, this new issue has been intensively studied.

Lee et al. (2001) reported that precursor NGF (proNGF) promoted neuronal death, whereas mature NGF promoted neuronal survival (13). Moreover, precursor BDNF (proBDNF) promoted cell death, growth cone retraction, spine shrinkage and LTD, whereas BDNF promoted spine formation, neuronal survival, and LTP (53) (54) (55) (56). In addition, the biological actions of proNGF and proBDNF required the activation of a receptor complex consisting of the $\mathrm{p} 75^{\mathrm{NTR}}$ neurotrophin receptor and sortilin to initiate cell death (54) (55). Another important finding concerning the pro-domain of NTs came from the study of a single nucleotide polymorphism (SNP) in the $b d n f$ gene, which changes a valine to a methionine at codon 66 (Val66Met) in the pro-region of human BDNF. Surprisingly, the Val66Met mutation impaired memory function, neuronal activity-dependent secretion of BDNF, and synapse sorting of BDNF protein (57). Since this study, there have been increasing numbers of reports suggesting that the Val66Met genetic variant increases susceptibility to brain disorders, including Alzheimer's disease (AD) (58).

These reports give rise to several important hypotheses: (1) precursor and mature NTs have opposing biological actions; (2) the BDNF pro-region plays a new role beyond that of a molecular chaperone to assist in the folding of BDNF (59); and (3) post-translational mechanisms, including proteolytic cleavage of precursor proteins, generate diverse biological actions of proteins.

\section{Activity-dependent mechanisms of BDNF synthesis for synaptic plasticity}

Activity-dependent synthesis of BDNF mRNA and secretion of BDNF protein are thought to be crucial mechanisms for synaptic modulation by BDNF (reviewed by (2)). Interestingly, neuronal activity is capable of controlling intracellular trafficking of 
BDNF mRNA and protein at distal dendrites and synaptic sites. The induction of LTP in hippocampal slices rapidly and selectively increases the level of BDNF mRNA (30). Furthermore, learning increases BDNF, proBDNF, and TrkB protein levels in hippocampus (60). The Tongiorgi group demonstrated that BDNF mRNA is transported into the dendrites of hippocampal neurons by neuronal depolarization in vitro (61) and by epileptogenic stimulation in vivo (62) (63) (64). These results show that dendritic movement of BDNF mRNA and the local translation of BDNF significantly contribute to activity-dependent synaptic plasticity.

\section{Opposing actions of BDNF and proBDNF in synaptic plasticity}

Recently, the role of post-translational modifications of BDNF, including proteolytic processing to produce the mature form of NTs, has been extensively explored. After synthesis of BDNF mRNA, BDNF protein is initially produced as a precursor protein (proBDNF), followed by post-translational cleavage of proBDNF into the mature form of BDNF by intracellular and/or extracellular proteases (12). Interestingly, Pang et al. (2004) showed that the extracellular conversion from proBDNF into BDNF occurred as a cellular mechanism determining BDNF-dependent LTD (14). Moreover, BDNF, through the activation of TrkB tyrosine kinase receptor, promotes cell survival, whereas proBDNF, through the activation of $\mathrm{p} 75^{\mathrm{NTR}}$, promotes neuronal death and the retraction of dendritic spines and growth cones (54) (55) (56), showing that this extracellular mechanism of protein cleavage is a crucial step for altering the cellular functions of BDNF (65).

More intriguingly, BDNF and proBDNF exert opposite effects on the regulation of synaptic plasticity (15). Woo et al. (2005) demonstrated that BDNF enhanced hippocampal LTP, while proBDNF facilitated LTD (53). They further showed that proBDNF facilitates hippocampal LTD by the activation of $\mathrm{p} 75^{\mathrm{NTR}}$ and that this facilitation of LTD by proBDNF required NR2B activation (53). Moreover, it was shown that high-frequency stimulation elicits BDNF release, while low-frequency stimulation stimulates proBDNF release (66). Recently, however, Yang et al. (2014) generated a knock-in mouse expressing a C-terminal hemagglutinin (HA)-epitope-tagged proBDNF and demonstrated that proBDNF was endogenously present in the hippocampus of mutant mice expressing HA-proBDNF (67). It was also shown that both proBDNF and $\mathrm{p} 75^{\mathrm{NTR}}$ are expressed postnatally (68) (67), suggesting 
that proBDNF/p $75^{\mathrm{NTR}}$ signaling is functional in postnatal developmental stages. A previous study showed that proNGF and proBDNF are cleaved in vitro by extracellular proteases, such as plasmin, to form mature NGF or BDNF. Together, these results suggest that (1) proNTs may be secreted, (2) they may function as signaling growth factors, and (3) BDNF and proBDNF exert a bidirectional role in synaptic plasticity through TrkB and $\mathrm{p} 75^{\mathrm{NTR}}$, respectively.

\section{BDNF and its pro-peptide are stored in presynaptic dense core vesicles}

Theoretically, BDNF and its pro-peptide (pro-domain) are produced from their precursor protein (proBDNF) by proteolytic cleavage. While it was previously reported that the BDNF pro-domain acts as a molecular chaperone to assist in the folding of BDNF (59),other biological roles of the BDNF pro-domain (pro-peptide) were not found. Nonetheless, there were at least two aspects of the BDNF protein itself. First, proBDNF consists of the pro-domain and mature domain of BDNF and displays opposed biological activity to BDNF (15). Second, an SNP that changes a valine to a methionine at codon 66 (Val66Met) in the pro-region of human BDNF impairs memory function, neuronal activity-dependent secretion of BDNF, and synapse sorting of BDNF protein (57). These reports raised the possibility that the BDNF pro-domain (pro-peptide) may exert additional functional alterations on the biological actions of BDNF.

Since this discovery, many aspects of BDNF function have been studied. However, since the levels of endogenous BDNF are very low, the subcellular localization of this secreted protein in neurons is not well elucidated. To understand the mode and action of secreted proteins, their subcellular localization is required. Recently, Dieni et al. (2012) examined the distribution of BDNF in the adult hippocampus using both light and ultra-structural microscopies and showed that antibodies reacting either with BDNF or its pro-peptide both stained large dense core vesicles in excitatory presynaptic terminals of the adult mouse hippocampus. Thus, importantly, this study provided a basis for an anterograde mode of action of BDNF, distinct from the retrograde model derived from experiments with NGF in the peripheral nervous system. They further showed that the moieties of BDNF and its pro-peptide were approximately 10-fold more abundant than pro-BDNF, suggesting that the BDNF pro-peptide functions in the developed and adult brain. 


\section{BDNF pro-peptide: a novel synaptic modulator in the central nervous system}

The BDNF pro-peptide is a portion of proBDNF. Recently, we demonstrated that the BDNF pro-peptide was a new synaptic modulator in the central nervous system: the BDNF pro-peptide directly facilitates hippocampal LTD (69). In this study, several lines of evidence indicated that the BDNF pro-peptide was a newly discovered facilitator of hippocampal LTD. For the LTD induction, a sequence of low-frequency stimulation (LFS; $1 \mathrm{~Hz}, 900$ pulses, $15 \mathrm{~min}$ ) was applied to Schaffer collaterals of hippocampal slices from juvenile mice, and then field excitatory postsynaptic potential (fEPSP) slopes in the CA1 were measured. We first showed that 30-min treatment with the BDNF pro-peptide (10 ng/ml, $30 \mathrm{~min}$ ) facilitated LTD in the hippocampus without affecting basal synaptic transmission. Second, a subnanomolar concentration of the BDNF pro-peptide was sufficient for LTD enhancement. Third, LTD occurred normally in $B d n f^{-/}$hippocampal slices, whereas application of the BDNF pro-peptide to the mutant slices facilitated LTD, suggesting that this effect of the BDNF pro-peptide was not mediated via an interaction with endogenous BDNF. Moreover, we showed that the BDNF pro-peptide-induced facilitation of hippocampal LTD required the activation of GluN2B-containingNMDA receptors and the pan-neurotrophin receptor $\mathrm{p} 75^{\mathrm{NTR}}$. The BDNF pro-peptide also enhanced NMDA-induced AMPAR endocytosis, a mechanism crucial for LTD expression. Thus, these findings suggest that the BDNF pro-peptide is implicated in synaptic plasticity that regulates a mechanism responsible for promoting LTD.

\section{Impact of the Val66Met polymorphism on BDNF pro-peptide-dependent LTD}

Our previous study demonstrated that the BDNF Val66Met polymorphism affected human memory function and the activity-dependent secretion of BDNF (57). A growing body of clinical evidence indicates that the Val66Met polymorphism increases susceptibility to a variety of brain disorders (58). Nonetheless, the molecular role of this BDNF polymorphism was not reported. Recently, it was demonstrated that mice with the Val66Met mutation are defective in NMDAR-dependent plasticity in the hippocampus (70). Unexpectedly, we found that the BDNF pro-peptide with the Met mutation completely inhibited hippocampal LTD (69). We further showed that the BDNF pro-peptide-induced endocytosis of GluA2, a crucial mechanism for the 
expression of LTD, was reversely altered by the amino acid substitution from valine to methionine in the BDNF pro-peptide (69). These results provide new mechanistic insights into the role of this BDNF polymorphism in synaptic plasticity.

\section{Discussion}

A body of evidence demonstrates the biological roles of mature NTs in the nervous system. In addition to these findings, recent reports have provided a new notion that a post-translational mechanism, proteolytic processing, may amplify the biological actions of NTs, as the BDNF pro-peptide and proBDNF were shown to be biological active molecules.

While it was predicted that the BDNF pro-domain was disordered by structure prediction software (71), we showed that the BDNF pro-peptide promoted hippocampal LTD, and Anastasia et al. (2013) reported that Met-BDNF pro-peptide induced acute growth cone retraction (71). Thus, the BDNF pro-peptide may exert its biological activity in a manner as reported by Sugase et al. (2007) (72). Their report investigated how intrinsically disordered proteins fold upon binding to their targets (72). A recent report also indicated that many eukaryotic proteins exist in a disordered form under physiological conditions and fold into ordered structures only upon binding to their cellular targets (73). Taken together, the BDNF pro-peptide might play important biological roles beyond its traditional role in assisting the folding of BDNF, and, in light of this possibility, we propose a "multi-ligand" model in which NTs, with their pro-domains, exert numerous biological functions in the nervous system (Figure 1).

We suggested that the BDNF pro-peptide and BDNF have antagonistic functions in LTD, i.e., facilitation and blockade of LTD induction (69). Given the antagonistic actions of BDNF and its pro-peptide, how these two peptides function under physiological conditions is a fundamental question. Recently, Guo et al. (2014) reported the role of neuronal activity on the levels of BDNF-induced TrkB activation: field stimulation with TBS (theta-burst stimulation) altered BDNF-induced TrkB phosphorylation from a transient to a sustained mode, while another stimulation protocol used to induce LTD paradigm did not (74). Understanding this mechanism of p75 ${ }^{\mathrm{NTR}}$, which requires the BDNF pro-peptide-dependent enhancement of hippocampal LTD, will be important to address the question of how BDNF and its pro-peptide operate coordinate their actions as a whole. Second, activity-dependent secretion of 
BDNF is a crucial mechanism of BDNF-dependent synaptic plasticity (2). The BDNF pro-peptide is stored in presynaptic dense core vesicles in brain neurons (75), and is secreted in an activity-dependent manner (71). Thus, the mechanism for the pro-peptide secretion should be detailed in future studies. Lastly, these new studies, including our report (69), will provide new insights for understanding the mechanisms of action of the pro-peptides of growth factors.

\section{Acknowledgments}

This work was supported by a Grant-in-Aid for Scientific Research on Priority AreasElucidation of neural network function in the brain-from the Ministry of Education, Culture, Sports, Science and Technology of Japan (40344171) (M.K.) and JST, CREST. The funding organizations had no role in the decision to publish, and the manuscript preparation. 


\section{References}

1. Bibel M, Barde YA. Neurotrophins: key regulators of cell fate and cell shape in the vertebrate nervous system. Genes Dev. 2000;14(23):2919-2937.

2. Park H, Poo MM. Neurotrophin regulation of neural circuit development and function. Nat Rev Neurosci. 2013;14(1):7-23.

3. Levi-Montalcini R, Hamburger V. A diffusible agent of mouse sarcoma, producing hyperplasia of sympathetic-ganglia and hyperneurotization of viscera in the chick embryo. J Exp Zool. 1953;123(2):233-287.

4. Cohen S, Levi-Montalcini R. A Nerve Growth-Stimulating Factor Isolated from Snake Venom. Proc Natl Acad Sci U S A. 1956;42(9):571-574.

5. Cohen S. Purification of a Nerve-Growth Promoting Protein from the Mouse Salivary Gland and Its Neuro-Cytotoxic Antiserum. Proc Natl Acad Sci U S A. 1960;46(3):302-311.

6. Bocchini V, Angeletti PU. The nerve growth factor: purification as a 30,000-molecular-weight protein. Proc Natl Acad Sci U S A. 1969;64(2):787-794.

7. Barde YA, Edgar D, Thoenen H. Purification of a new neurotrophic factor from mammalian brain. EMBO J. 1982;1(5):549-553.

8. Leibrock J, Lottspeich F, Hohn A, Hofer M, Hengerer B, Masiakowski P, Thoenen H, Barde YA. Molecular cloning and expression of brain-derived neurotrophic factor. Nature. 1989;341(6238):149-152.

9. Maisonpierre PC, Belluscio L, Squinto S, Ip NY, Furth ME, Lindsay RM, Yancopoulos GD. Neurotrophin-3: a neurotrophic factor related to NGF and BDNF. Science. 1990;247(4949 Pt 1):1446-1451.

10. Ip NY, Ibanez CF, Nye SH, McClain J, Jones PF, Gies DR, Belluscio L, Le Beau MM, Espinosa R, 3rd, Squinto SP, et al. Mammalian neurotrophin-4: structure, chromosomal localization, tissue distribution, and receptor specificity. Proc Natl Acad Sci U S A. 1992;89(7):3060-3064.

11. Lessmann V, Gottmann K, Malcangio M. Neurotrophin secretion: current facts and future prospects. Prog Neurobiol. 2003;69(5):341-374.

12. Seidah NG, Benjannet S, Pareek S, Chretien M, Murphy RA. Cellular processing of the neurotrophin precursors of NT3 and BDNF by the mammalian proprotein 
convertases. FEBS Lett. 1996;379(3):247-250.

13. Lee R, Kermani P, Teng KK, Hempstead BL. Regulation of cell survival by secreted proneurotrophins. Science. 2001;294(5548):1945-1948.

14. Pang PT, Teng HK, Zaitsev E, Woo NT, Sakata K, Zhen S, Teng KK, Yung WH, Hempstead BL, Lu B. Cleavage of proBDNF by tPA/plasmin is essential for long-term hippocampal plasticity. Science. 2004;306(5695):487-491.

15. Lu B, Pang PT, Woo NH. The yin and yang of neurotrophin action. Nat Rev Neurosci. 2005;6(8):603-614.

16. Mowla SJ, Pareek S, Farhadi HF, Petrecca K, Fawcett JP, Seidah NG, Morris SJ, Sossin WS, Murphy RA. Differential sorting of nerve growth factor and brain-derived neurotrophic factor in hippocampal neurons. J Neurosci. 1999;19(6):2069-2080.

17. Lessmann V, Brigadski T. Mechanisms, locations, and kinetics of synaptic BDNF secretion: an update. Neurosci Res. 2009;65(1):11-22.

18. Chao MV. Neurotrophins and their receptors: a convergence point for many signalling pathways. Nat Rev Neurosci. 2003;4(4):299-309.

19. Liepinsh E, Ilag LL, Otting G, Ibanez CF. NMR structure of the death domain of the p75 neurotrophin receptor. EMBO J. 1997;16(16):4999-5005.

20. He XL, Garcia KC. Structure of nerve growth factor complexed with the shared neurotrophin receptor p75. Science. 2004;304(5672):870-875.

21. Hempstead BL. Deciphering proneurotrophin actions. Handb Exp Pharmacol. 2014;220:17-32.

22. Reichardt LF. Neurotrophin-regulated signalling pathways. Philos Trans R Soc Lond B Biol Sci. 2006;361(1473):1545-1564.

23. Hempstead BL. The many faces of p75NTR. Curr Opin Neurobiol. 2002;12(3):260-267.

24. Teng KK, Felice S, Kim T, Hempstead BL. Understanding proneurotrophin actions: Recent advances and challenges. Dev Neurobiol. 2010;70(5):350-359.

25. Ibanez CF, Simi A. p75 neurotrophin receptor signaling in nervous system injury and degeneration: paradox and opportunity. Trends Neurosci. 2012;35(7):431-440.

26. Bliss TV, Collingridge GL. A synaptic model of memory: long-term potentiation in the hippocampus. Nature. 1993;361(6407):31-39. 
27. Malenka RC, Bear MF. LTP and LTD: an embarrassment of riches. Neuron. 2004;44(1):5-21.

28. Frey U, Krug M, Reymann KG, Matthies H. Anisomycin, an inhibitor of protein synthesis, blocks late phases of LTP phenomena in the hippocampal CA1 region in vitro. Brain Res. 1988;452(1-2):57-65.

29. Huang YY, Kandel ER. Recruitment of long-lasting and protein kinase A-dependent long-term potentiation in the CA1 region of hippocampus requires repeated tetanization. Learn Mem. 1994;1(1):74-82.

30. Patterson SL, Grover LM, Schwartzkroin PA, Bothwell M. Neurotrophin expression in rat hippocampal slices: a stimulus paradigm inducing LTP in CA1 evokes increases in BDNF and NT-3 mRNAs. Neuron. 1992;9(6):1081-1088.

31. Castren E, Pitkanen M, Sirvio J, Parsadanian A, Lindholm D, Thoenen H, Riekkinen PJ. The induction of LTP increases BDNF and NGF mRNA but decreases NT-3 mRNA in the dentate gyrus. Neuroreport. 1993;4(7):895-898.

32. Zafra F, Hengerer B, Leibrock J, Thoenen H, Lindholm D. Activity dependent regulation of BDNF and NGF mRNAs in the rat hippocampus is mediated by non-NMDA glutamate receptors. EMBO J. 1990;9(11):3545-3550.

33. Isackson PJ, Huntsman MM, Murray KD, Gall CM. BDNF mRNA expression is increased in adult rat forebrain after limbic seizures: temporal patterns of induction distinct from NGF. Neuron. 1991;6(6):937-948.

34. Goodman LJ, Valverde J, Lim F, Geschwind MD, Federoff HJ, Geller AI, Hefti F. Regulated release and polarized localization of brain-derived neurotrophic factor in hippocampal neurons. Mol Cell Neurosci. 1996;7(3):222-238.

35. Canossa M, Griesbeck O, Berninger B, Campana G, Kolbeck R, Thoenen H. Neurotrophin release by neurotrophins: implications for activity-dependent neuronal plasticity. Proc Natl Acad Sci U S A. 1997;94(24):13279-13286.

36. Lessmann V, Gottmann K, Heumann R. BDNF and NT-4/5 enhance glutamatergic synaptic transmission in cultured hippocampal neurones. Neuroreport. 1994;6(1):21-25.

37. Levine ES, Dreyfus CF, Black IB, Plummer MR. Brain-derived neurotrophic factor rapidly enhances synaptic transmission in hippocampal neurons via postsynaptic tyrosine kinase receptors. Proc Natl Acad Sci U S A. 1995;92(17):8074-8077. 
38. Figurov A, Pozzo-Miller LD, Olafsson P, Wang T, Lu B. Regulation of synaptic responses to high-frequency stimulation and LTP by neurotrophins in the hippocampus. Nature. 1996;381(6584):706-709.

39. Yan Q, Rosenfeld RD, Matheson CR, Hawkins N, Lopez OT, Bennett L, Welcher AA. Expression of brain-derived neurotrophic factor protein in the adult rat central nervous system. Neuroscience. 1997;78(2):431-448.

40. Ernfors P, Lee KF, Jaenisch R. Mice lacking brain-derived neurotrophic factor develop with sensory deficits. Nature. 1994;368(6467):147-150.

41. Jones KR, Farinas I, Backus C, Reichardt LF. Targeted disruption of the BDNF gene perturbs brain and sensory neuron development but not motor neuron development. Cell. 1994;76(6):989-999.

42. Patterson SL, Abel T, Deuel TA, Martin KC, Rose JC, Kandel ER. Recombinant BDNF rescues deficits in basal synaptic transmission and hippocampal LTP in BDNF knockout mice. Neuron. 1996;16(6):1137-1145.

43. Korte M, Carroll P, Wolf E, Brem G, Thoenen H, Bonhoeffer T. Hippocampal long-term potentiation is impaired in mice lacking brain-derived neurotrophic factor. Proc Natl Acad Sci U S A. 1995;92(19):8856-8860.

44. Korte M, Griesbeck O, Gravel C, Carroll P, Staiger V, Thoenen H, Bonhoeffer T. Virus-mediated gene transfer into hippocampal CA1 region restores long-term potentiation in brain-derived neurotrophic factor mutant mice. Proc Natl Acad Sci U S A. 1996;93(22):12547-12552.

45. Yang F, He X, Feng L, Mizuno K, Liu XW, Russell J, Xiong WC, Lu B. PI-3 kinase and IP3 are both necessary and sufficient to mediate NT3-induced synaptic potentiation. Nat Neurosci. 2001;4(1):19-28.

46. Xu B, Gottschalk W, Chow A, Wilson RI, Schnell E, Zang K, Wang D, Nicoll RA, Lu B, Reichardt LF. The role of brain-derived neurotrophic factor receptors in the mature hippocampus: modulation of long-term potentiation through a presynaptic mechanism involving TrkB. J Neurosci. 2000;20(18):6888-6897.

47. Minichiello L, Calella AM, Medina DL, Bonhoeffer T, Klein R, Korte M. Mechanism of TrkB-mediated hippocampal long-term potentiation. Neuron. 2002;36(1):121-137.

48. Suen PC, Wu K, Levine ES, Mount HT, Xu JL, Lin SY, Black IB. Brain-derived neurotrophic factor rapidly enhances phosphorylation of the postsynaptic 
N-methyl-D-aspartate receptor subunit 1. Proc Natl Acad Sci U S A. 1997;94(15):8191-8195.

49. Lin SY, Wu K, Levine ES, Mount HT, Suen PC, Black IB. BDNF acutely increases tyrosine phosphorylation of the NMDA receptor subunit 2B in cortical and hippocampal postsynaptic densities. Brain Res Mol Brain Res. 1998;55(1):20-27.

50. Narisawa-Saito M, Iwakura Y, Kawamura M, Araki K, Kozaki S, Takei N, Nawa H. Brain-derived neurotrophic factor regulates surface expression of alpha-amino-3-hydroxy-5-methyl-4-isoxazoleproprionic acid receptors by enhancing the $\mathrm{N}$-ethylmaleimide-sensitive factor/GluR2 interaction in developing neocortical neurons. J Biol Chem. 2002;277(43):40901-40910.

51. Holm MM, Nieto-Gonzalez JL, Vardya I, Vaegter CB, Nykjaer A, Jensen K. Mature BDNF, but not proBDNF, reduces excitability of fast-spiking interneurons in mouse dentate gyrus. J Neurosci. 2009;29(40):12412-12418.

52. Chevaleyre V, Castillo PE. Heterosynaptic LTD of hippocampal GABAergic synapses: a novel role of endocannabinoids in regulating excitability. Neuron. 2003;38(3):461-472.

53. Woo NH, Teng HK, Siao CJ, Chiaruttini C, Pang PT, Milner TA, Hempstead BL, Lu B. Activation of p75NTR by proBDNF facilitates hippocampal long-term depression. Nat Neurosci. 2005;8(8):1069-1077.

54. Teng HK, Teng KK, Lee R, Wright S, Tevar S, Almeida RD, Kermani P, Torkin R, Chen ZY, Lee FS, Kraemer RT, Nykjaer A, Hempstead BL. ProBDNF induces neuronal apoptosis via activation of a receptor complex of p75NTR and sortilin. J Neurosci. 2005;25(22):5455-5463.

55. Deinhardt K, Kim T, Spellman DS, Mains RE, Eipper BA, Neubert TA, Chao MV, Hempstead BL. Neuronal growth cone retraction relies on proneurotrophin receptor signaling through Rac. Sci Signal. 2011;4(202):ra82.

56. Koshimizu H, Kiyosue K, Hara T, Hazama S, Suzuki S, Uegaki K, Nagappan G, Zaitsev E, Hirokawa T, Tatsu Y, Ogura A, Lu B, Kojima M. Multiple functions of precursor BDNF to CNS neurons: negative regulation of neurite growth, spine formation and cell survival. Mol Brain. 2009;2:27.

57. Egan MF, Kojima M, Callicott JH, Goldberg TE, Kolachana BS, Bertolino A, Zaitsev E, Gold B, Goldman D, Dean M, Lu B, Weinberger DR. The BDNF 
val66met polymorphism affects activity-dependent secretion of BDNF and human memory and hippocampal function. Cell. 2003;112(2):257-269.

58. Bath KG, Lee FS. Variant BDNF (Val66Met) impact on brain structure and function. Cogn Affect Behav Neurosci. 2006;6(1):79-85.

59. Kolbeck R, Jungbluth S, Barde YA. Characterisation of neurotrophin dimers and monomers. Eur J Biochem. 1994;225(3):995-1003.

60. Silhol M, Arancibia S, Maurice T, Tapia-Arancibia L. Spatial memory training modifies the expression of brain-derived neurotrophic factor tyrosine kinase receptors in young and aged rats. Neuroscience. 2007;146(3):962-973.

61. Tongiorgi E, Righi M, Cattaneo A. Activity-dependent dendritic targeting of BDNF and TrkB mRNAs in hippocampal neurons. J Neurosci. 1997;17(24):9492-9505.

62. Simonato M, Bregola G, Armellin M, Del Piccolo P, Rodi D, Zucchini S, Tongiorgi E. Dendritic targeting of mRNAs for plasticity genes in experimental models of temporal lobe epilepsy. Epilepsia. 2002;43 Suppl 5:153-158.

63. Tongiorgi E, Armellin M, Giulianini PG, Bregola G, Zucchini S, Paradiso B, Steward O, Cattaneo A, Simonato M. Brain-derived neurotrophic factor mRNA and protein are targeted to discrete dendritic laminas by events that trigger epileptogenesis. J Neurosci. 2004;24(30):6842-6852.

64. Chiaruttini C, Sonego M, Baj G, Simonato M, Tongiorgi E. BDNF mRNA splice variants display activity-dependent targeting to distinct hippocampal laminae. Mol Cell Neurosci. 2008;37(1):11-19.

65. Greenberg ME, Xu B, Lu B, Hempstead BL. New insights in the biology of BDNF synthesis and release: implications in CNS function. J Neurosci. 2009;29(41):12764-12767.

66. Nagappan G, Zaitsev E, Senatorov VV, Jr., Yang J, Hempstead BL, Lu B. Control of extracellular cleavage of ProBDNF by high frequency neuronal activity. Proc Natl Acad Sci U S A. 2009;106(4):1267-1272.

67. Yang J, Harte-Hargrove LC, Siao CJ, Marinic T, Clarke R, Ma Q, Jing D, Lafrancois JJ, Bath KG, Mark W, Ballon D, Lee FS, Scharfman HE, Hempstead BL. proBDNF negatively regulates neuronal remodeling, synaptic transmission, and synaptic plasticity in hippocampus. Cell Rep. 2014;7(3):796-806.

68. Yang J, Siao CJ, Nagappan G, Marinic T, Jing D, McGrath K, Chen ZY, Mark W, 
Tessarollo L, Lee FS, Lu B, Hempstead BL. Neuronal release of proBDNF. Nat Neurosci. 2009;12(2):113-115.

69. Mizui T, Ishikawa Y, Kumanogoh H, Lume M, Matsumoto T, Hara T, Yamawaki S, Takahashi M, Shiosaka S, Itami C, Uegaki K, Saarma M, Kojima M. BDNF pro-peptide actions facilitate hippocampal LTD and are altered by the common BDNF polymorphism Val66Met. Proc Natl Acad Sci U S A.

2015;112(23):E3067-3074.

70. Ninan I, Bath KG, Dagar K, Perez-Castro R, Plummer MR, Lee FS, Chao MV. The BDNF Val66Met polymorphism impairs NMDA receptor-dependent synaptic plasticity in the hippocampus. J Neurosci. 2010;30(26):8866-8870.

71. Anastasia A, Deinhardt K, Chao MV, Will NE, Irmady K, Lee FS, Hempstead BL, Bracken C. Val66Met polymorphism of BDNF alters prodomain structure to induce neuronal growth cone retraction. Nat Commun. 2013;4:2490.

72. Sugase K, Dyson HJ, Wright PE. Mechanism of coupled folding and binding of an intrinsically disordered protein. Nature. 2007;447(7147):1021-1025.

73. Wright PE, Dyson HJ. Intrinsically unstructured proteins: re-assessing the protein structure-function paradigm. J Mol Biol. 1999;293(2):321-331.

74. Kinoshita S, Yasuda H, Taniguchi N, Katoh-Semba R, Hatanaka H, Tsumoto T. Brain-derived neurotrophic factor prevents low-frequency inputs from inducing long-term depression in the developing visual cortex. J Neurosci. 1999;19(6):2122-2130.

75. Dieni S, Matsumoto T, Dekkers M, Rauskolb S, Ionescu MS, Deogracias R, Gundelfinger ED, Kojima M, Nestel S, Frotscher M, Barde YA. BDNF and its pro-peptide are stored in presynaptic dense core vesicles in brain neurons. J Cell Biol. 2012;196(6):775-788. 


\section{Figure 1 Distinct implication of BDNF isoforms in LTP and LTD.}

Previous and recent reports $(38,39,45,53,69)$ indicate the implication of BDNF, proBDNF and BDNF pro-peptide in LTP and LTD. BDNF activates the TrkB receptor to promote LTP. The BDNF pro-peptide and proBDNF requires p75NTR receptor to promote LTD. A recent study (69) further shows that a common BDNF polymorphism Val66Met, which substitute valine into methionine at amino acid codon 66, inhibits the BDNF pro-peptide-facilitated hippocampal LTD. In Figure, arrows indicate intra- and extra-cellular events after mRNA synthesis.

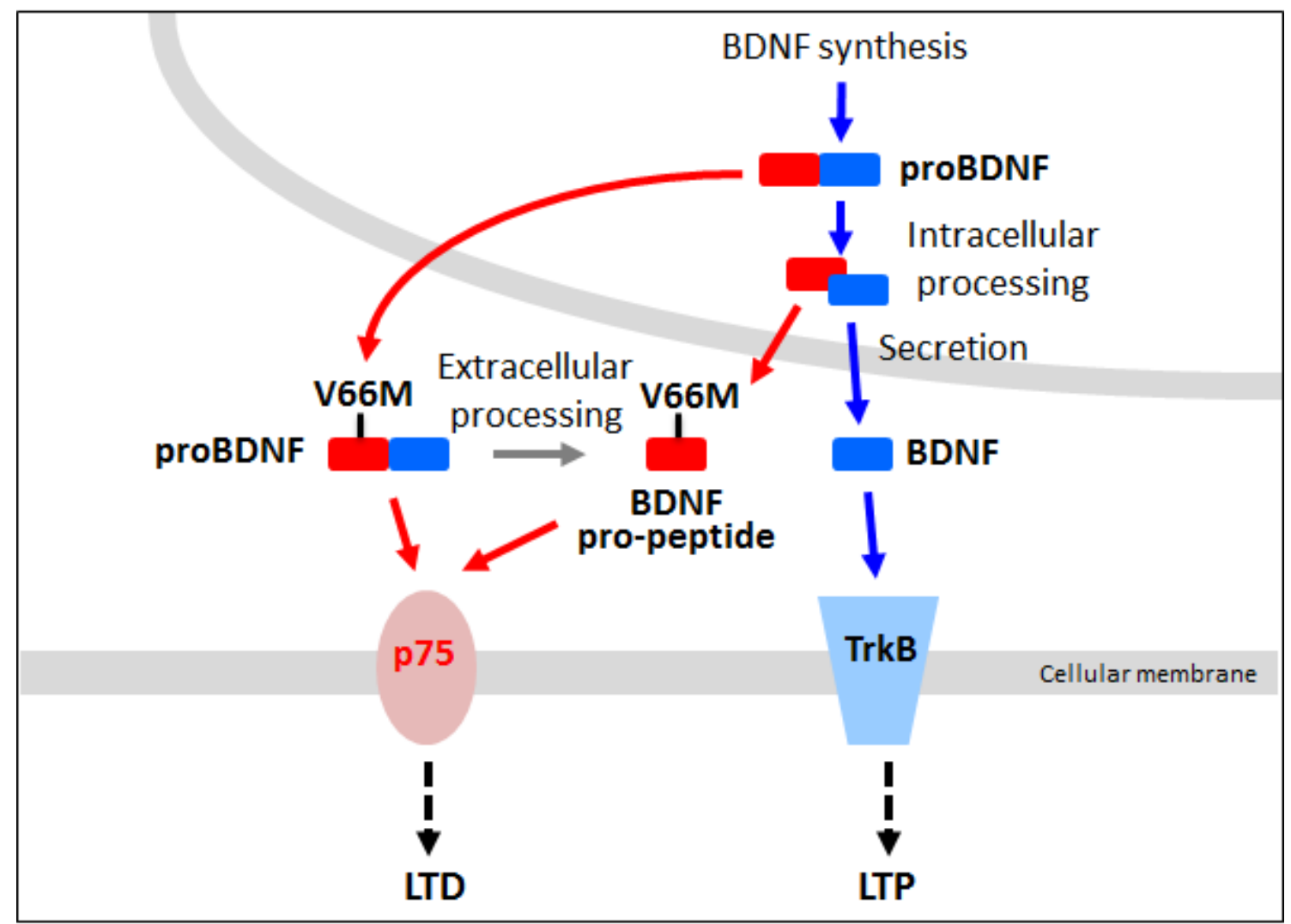

